\title{
Advances in Industrialized Rice Production Research
}

\author{
Jing Ma, Rongchao Ma, Weixiong Wu, Xiaolong Lei, Wen Gou \\ Sichuan Agricultural University, Ya'an, China \\ Email: 13608265802@163.com, wuwxy@126.com, leixl1989@163.com, \\ gouwenll@126.com, mycao@sicau.edu.cn
}

Received 3 August 2015; accepted 23 October 2015; published 26 October 2015

Copyright (C) 2015 by authors and Scientific Research Publishing Inc.

This work is licensed under the Creative Commons Attribution International License (CC BY).

http://creativecommons.org/licenses/by/4.0/

(c) (i) Open Access

\begin{abstract}
To widen the new way of thinking and to explore a new technology of rice planting, industrialized rice production is an advanced rice planting method. All processes of rice growth were finished in factory and they provided proper growth conditions (including light, $\mathrm{CO}_{2}$ concentration, temperature, moisture and minerals) on the base of different growth stages. This paper illustrated the theory of rice growth in factory, the processes of rice cultivation and fundamental structure of rice factory. It combined natural conditions with artificial environment to create an ideal rice growing environment. Rice cultivation's cycle in factory was shortened and normally one day was divided into 2 - 3 special days. It could be continuous production and prevented rice planting from being affected by external conditions. Industrialized rice makes full use of energy on the basis of sunray and artificial supplies to increase the rice yield and it will start a revolution of rice planting and solve the problem of food safety.
\end{abstract}

\section{Keywords}

Agriculture, Rice Production, Industrialized Production, Photosynthesis Efficiency, Food Safety

\section{Introduction}

Traditional rice planting has been on the way for thousands of years. It depends on natural conditions, conventional breeding and cultivation. Though technology of rice breeding and cultivation, and the research of hybrid rice or super hybrid rice have improved considerably, the way of rice production has not been changed fundamentally, which relies heavily on temperature, geographical position, climate, etc. Meanwhile, the farm production has been sharply decreased because of impact of anomaly climate. Moreover, the whole world faces a serious shortage of agricultural products since the outdoor products are reduced by unexpected changes of climate 
such as high-temperature, flood, and drought. In addition, the farmland has been reduced dramatically in recent years. Rice planting is limited by geographical position, too. Food security is determined by natural conditions considerably. In order to overcome such problems of climate and to protect natural ecosystem, plant factory may be a useful part of industries, and it could be suitable for rice cultivation.

Rice factory, a case of plant factory, is a kind of system where crops can be produced continuously. The productions from the rice factory are close to natural productions and the climatic impact will not be effective by controlling the environmental conditions such as light, temperature, humidity and nutrient in limited space. And the plant factory is categorized into hybrid controlled type and fully controlled type according to manage growth of plant and control environment in the facilities, as it is difficult to predict changes of outdoors environment [1]-[2]. Therefore, the study on fully controlled type is a hotter topic these days.

Industrialized rice production depends on a perfect artificial-environment which is created for the plants by controlling systems. Until now, many researches were conducted in vegetables and fruits, such as tomato, cucumber, pea, lettuce and grapes [3]. Rice or other grains were not included. One of the reasons is the economic profit and life cycles. The other is the requirement of quantity of PPF (Photosynthetic Photo Flux). In this paper, rice (Oryza sativa L.) is the experimental material to explore industrialized rice production. This paper is comprised of 3 chapters. We explain the theory of rice in factory, the structure of rice factory in Chapter 2, and the future works in Chapters 3.

Industrialized rice production is a breakthrough from the traditional planting and the quality of rice can be controlled. It will be a trend of rice planting in future and it will promote the development of agricultural engineering deeply, ensure crop security and promote agricultural sustainable development.

\section{Processes of Industrialized Rice Production}

Industrialized rice production processes include the growing, from seed germination to ripe rice, harvesting, threshing, drying and rice milling, and are in auto-controlled factory. Rice growing in the chain of factory is based on the rice growth rhythm, conditions and needs from seed germination to ripe rice. Processes of industrialized rice production are shown in Figure 1.

The processes of industrialized rice production generally include five steps: preparing works, seeding, managing, harvesting and post-processing. Preparing works is the primary step concerning seeds treatment, collocating nutrient solution, preparing nutritional soil, etc. Seeding in factory is direct-seeding which saves the step of transplanting and shortens the growth cycle. Managing in factory is vastly different from that in normal rice cultivation. It relies on the artificial growth environment which consists of light, temperature, humidity, water and fertilizer conditions. Besides, it changes the cycle of illumination in different growth period. The step of managing is a key and lengthy process and changes thoroughly the traditional cropping patterns. When rice has been ripe, it is harvested and the straw is smashed as organic fertilizer. Then, high quality white rice is produced in post-processing mill.

Rice growth is not only affected by the quality of rice seed, but also by the circumstantial parameters of light (including illumination intensity, light quality and illumination time), $\mathrm{CO}_{2}$ concentration, temperature, moisture and minerals. Light is the most significant factor for rice photosynthesis because light is the most important factor of chloroplasts development and chlorophyll synthesis. Besides, light quality plays a critical role in the rate of photosynthesis. Red light (wavelength of $600-680 \mathrm{~nm}$ ) and blue light (wavelength of $430-450 \mathrm{~nm}$ ) develop photosynthesis rate due to increasing absorbing chloroplast pigment [4]. With the proper $\mathrm{CO}_{2}$ concentration, temperature, moisture and minerals, lengthening illumination time promotes dry matter's accumulation [5] [6].

According to rice growth's characteristics, the climatic conditions of abundant light, high relative humidity and proper temperature help to increase rice yield. If illumination intensity, light quality and illumination time are adjusted properly within the desired climatic conditions, rice produced in factory can be realized. That is to say, the time of day and night could be changed and one normal day should be separated into 2 - 3 special days by industrialized producing. The cycle of one day will be shortened and the efficiency of solar energy improves a lot. Comparison of photosynthesis between normal and industrialized rice planting is shown in Figure 2. Besides, the light quality, $\mathrm{CO}_{2}$ concentration, temperature, moisture and minerals could be changed in different growth duration. By providing desired external conditions, the rice yield will increase and the growth duration will be shortened by more than half of that in original planting.

Because rice grows in factory, light, $\mathrm{CO}_{2}$ concentration, temperature, moisture and minerals are controlled artificially. All parameters of rice growing are tested by different sensors and growing conditions are regulated 


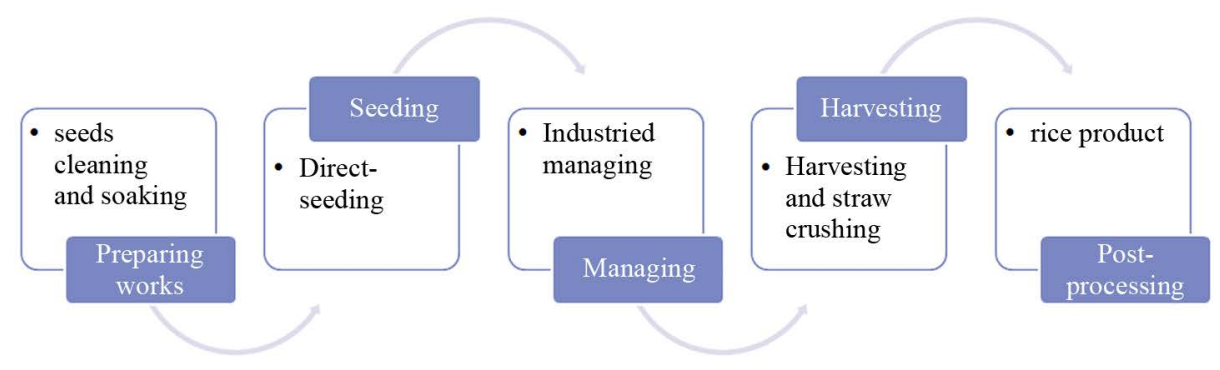

Figure 1. Processes of industrialized rice production.

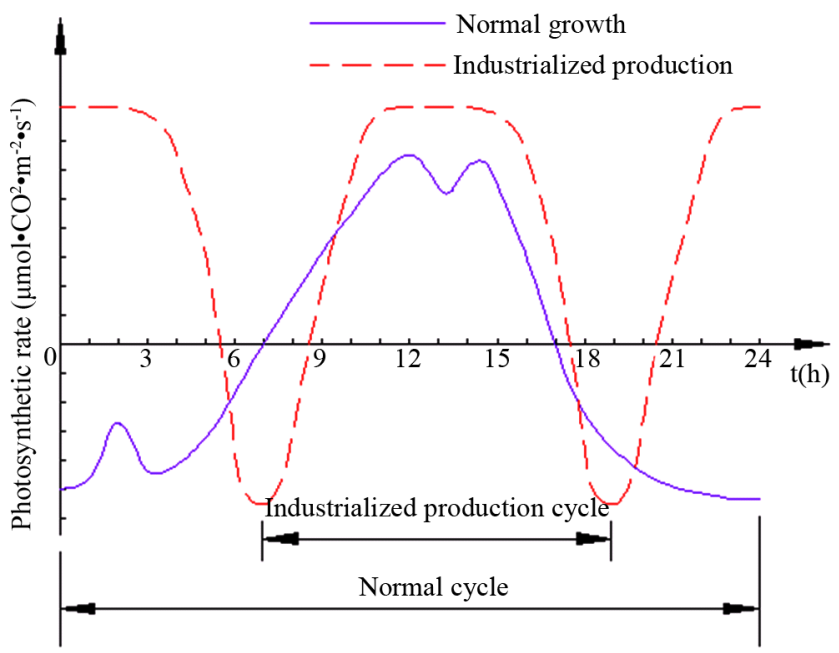

Figure 2. Photosynthesis comparison between normal and industrialized rice planting.

according to the demand of different growth duration. Rice growth duration consists of seeding stage, tillering stage, spikelet differentiation stage, heading and flowering period, and filling and ripening stage. Besides proper light and $\mathrm{CO}_{2}$ concentration, proper temperature is also an important factor for photosynthesis of rice, and big difference in temperature between daytime and night could develop rice's photosynthetic rate. Different temperature, moisture and minerals are managed in factory on the basis of different growing stage demand.

\section{The Structure of Rice Factory}

In this chapter, the structure of rice factory is illustrated to cultivate rice in artificial circumstance. In addition, blueprint of rice factory illustrated in Figure 3 and specification of rice cultivation was shown in Figure 4. The artificial lighting control system is based on context-awareness to promote plant growth and to reduce energy consumption by supplying supplemental lighting in real-time according to the dynamic changes of sunray.

The blueprint of rice factory mainly includes LCS (Light Control System), nutrient solution growing tray, heating and cooling system, growth space, $\mathrm{CO}_{2}$ controller, power supply, nutrient solution tank and PC monitoring system. Context Receptors collects external environmental information such as intensity of sunray, temperature, humidity, $\mathrm{CO}_{2}$ concentration and nutrient related to the growth of rice by the integrated sensors, which are installed at several points in rice factory. Collected data are converted into appropriate data types and then are stored into database of external context information.

Then the data are classified according to different factors and the growth stages of rice are diagnosed on the base of morphological and physiological characteristics. Context information interpreter analyzes the amount of supplemental lighting according to dynamic changing of weather using light compensation level and light saturation point. The PC monitoring system executes the artificial lighting control service based on context-awareness possibly for dramatic environmental changes.

To make full use of light, the LCS could be adjustable on the base of growth periods and plant height. The rice factory consists of amount of structure unit like Figure 3 . The standard of rice cultivation is set up on the 


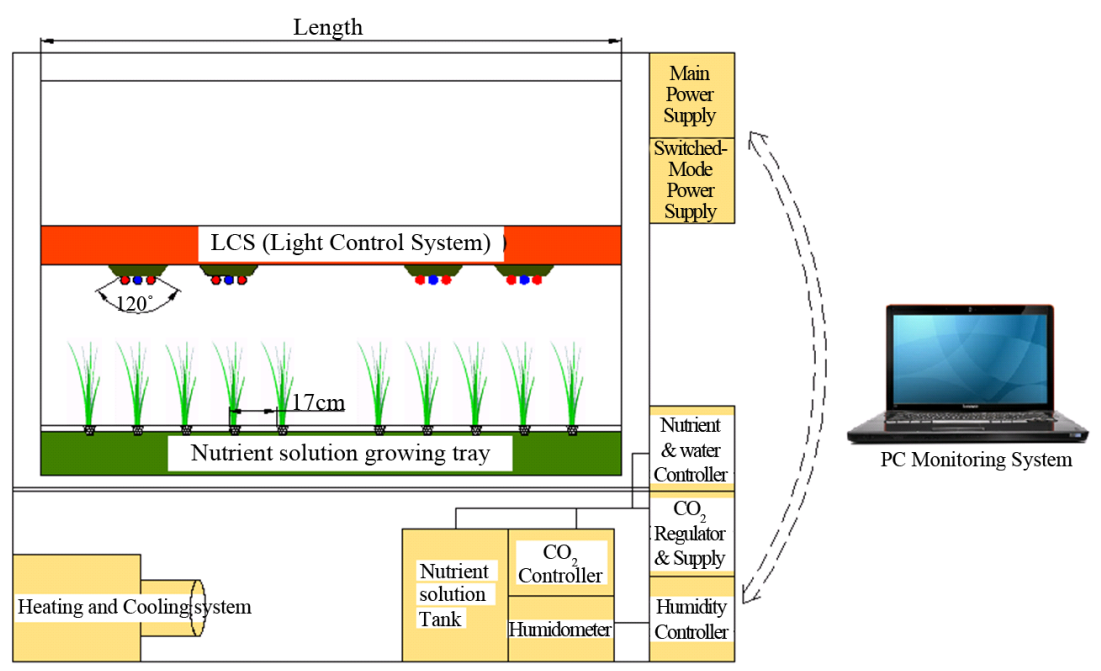

Figure 3. Blueprint of rice factory.

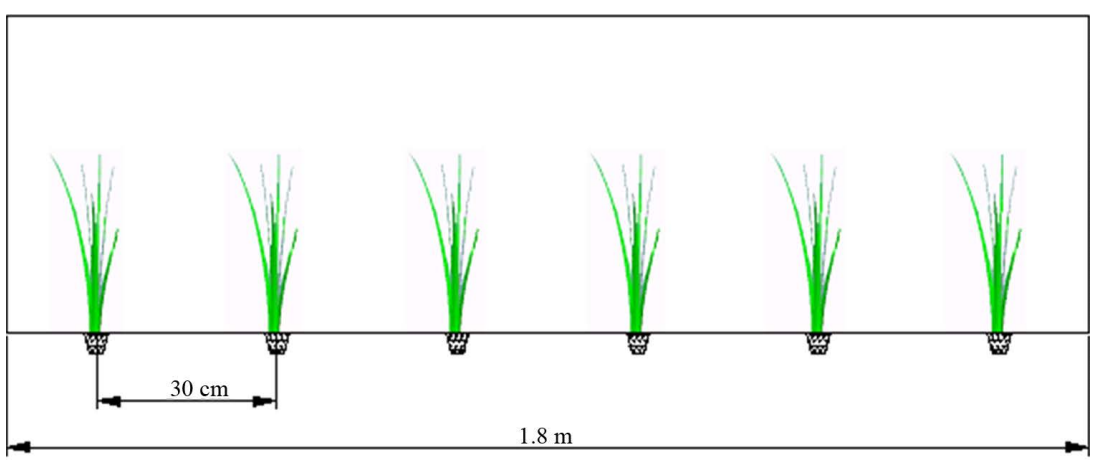

Figure 4. Specification of rice cultivation.

Table 1. Specification of rice factory.

\begin{tabular}{cc}
\hline Section & Standard \\
\hline Mini-Plant & $40 \times 1.8 \times 1.5(\mathrm{~m})$ (length $\times$ width $\times$ height) \\
Growth floor & $40 \times 1.8 \times 0.3(\mathrm{~m})$ (length $\times$ width $\times$ height) \\
Cultivation specification & $30 \mathrm{~cm} \times 17 \mathrm{~cm}$ (line spacing $\times$ hill spacing) \\
LED Bar & Blue: $450 \mathrm{~nm}$ Red: $630-660 \mathrm{~nm}$ \\
& (rate of the number of blue leds and red leds, 11:7) \\
\hline
\end{tabular}

basis of high yield cultivation and the specification of rice factory is illustrated in Table 1 . The line and hill spacing is adopted at $30 \mathrm{~cm}$ and $17 \mathrm{~cm}$ separately. There is hole sowing in the rice factory and the soil in each hill to improve lodging resistance. Meanwhile, the nutrient solution and water supply are changed according to growth stage and physiological requirements.

\section{Conclusions}

This paper illustrated the theory of rice growth in factory, the processes of rice cultivation and fundamental structure of rice factory. By building a rice factory, an ideal growth circumstance of rice cultivation is realized, and the architecture of artificial light control system based on context-awareness is established to provide the appropriate amount of supplemental lighting on the basis of the stages of growth. The energy supply relies on sunray and artificial supplement which provides proper illumination.

Industrialized rice production brings new insight in technology of rice planting. It controls natural conditions 
by combining artificial approach and natural conditions to create an ideal environment for rice growing. Proper light, $\mathrm{CO}_{2}$ concentration, temperature, moisture and minerals are provided and changed according to the different growth periods. Most important of all, one normal day is divided into 2 - 3 special days in factory. And it promotes rice's photosynthetic rate and shortened the growth cycle. Industrialized rice production prevented rice planting from being affected by external conditions and favorable conditions are provided. It raises efficiency of solar energy, increases the unit area rice yield, and can be continuous production. Thus, industrialized rice production may start a revolution of rice planting. Meanwhile, the rice factory ideal parameters are not complete and the huge energy supply is still a big issue. We should improve it constantly to make it economic and popular.

\section{References}

[1] Moon, A., Li, S. and Kim, K. (2011) Components Based Integrated Management Platform for Flexible Service Development in Plant Factory. CCIS, 173, 524-528.

[2] Kim, K. and Lim, J.-H. (2011) Energy Saving of Plant Cultivation System Using LED Control System Based on Ultrasonic Sensor. LNEE, 132, 615-623. http://dx.doi.org/10.1007/978-3-642-25899-2_83

[3] Kwon, S. and Lim, J. (2011) Improvement of Energy Efficiency in Plant Factories through the Measurement of Plant Bioelectrical Potential. LNEE, 132, 641-648. http://dx.doi.org/10.1007/978-3-642-25899-2_86

[4] Guo, Y.S., Gu, A.S. and Cui, J. (2011) Effects of Light Quality on Rice Seeding Growth and Physiological Characteristics. Chinese Journal of Applied Ecology, 6, 1485-1492.

[5] Xie, L.Y., Lin, E.D., Sun, F. and Zhao, H.Y. (2006) Effects of $\mathrm{CO}_{2}$ Enrichment and Temperature Increase during Growth Duration on Physiological Characteristics of Rice. Journal of China Agricultural University, 1, 17-21.

[6] Ohnuki-Tierney, E. (2004) Rice as Self. Japanese Identities through Time, 9, 4-9. 